\title{
Interactive comment on "Aircraft observations of water-soluble dicarboxylic acids in the aerosols over China” by Yan-Lin Zhang et al.
}

Yan-Lin Zhang et al.

dryanlinzhang@gmail.com

Received and published: 6 May 2016

The comment was uploaded in the form of a supplement:

http://www.atmos-chem-phys-discuss.net/acp-2016-5/acp-2016-5-AC1-

supplement.pdf

Interactive comment on Atmos. Chem. Phys. Discuss., doi:10.5194/acp-2016-5, 2016. 